Authors' Contribution: A Study Design B Data Collection C Statistical Analysis D Data Interpretation E Manuscript Preparation F Literature Search G Funds Collection

\section{Lower limbs asymmetries in the agility and explosive strength in male football players}

\author{
Sorin Albeanu ${ }^{1 \mathrm{ABF}}$, Robert Munteanu ${ }^{2 \mathrm{ABF}}$, Luminița Călinescu Brabiescu ${ }^{1 \mathrm{ACD}}$,

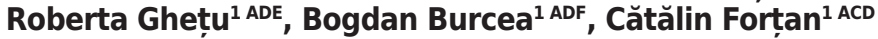 \\ ${ }^{1}$ Faculty of Physical Education and Sport, University of Craiova, Craiova, Romania \\ ${ }^{2}$ National University of Physical Education and Sport, Bucharest, Romania
}

\title{
abstract
}

Background: Football game requires a permanent dynamic, in which players frequently perform changes of direction, with or without the ball. This requires explosive strength in the lower limbs as well as agility. The aim of the study was to measure the execution time within the changes of direction over different distances.

Material and methods:

A total of 20 male football players were selected (aged 17.6 \pm 1.27 years old), BMI $21.4 \pm 1.99$. For the explosive strength, two tests using Optojump (Microgate) were applied: CMJ and 5 jumps single leg left/right front/back drift. Each player also performed an agility test consisting of a single change of direction to the left and another one to the right, then a complete turn with three changes of direction, once to the left and once to the right.

Results: Regardless of the dominant part, in the simple agility test there were no significant differences between the left and right leg $(p>0.05)$, while in the multiple tests, these differences became significant, with a delay in execution on the left side $(p<0.05)$. Also, a moderate correlation was found between explosive strength and agility $(r=.544, p<.05)$.

Conclusions: In the games of possession, positioning and rounds, they will be permanently changed in such a way as to use both legs for the symmetrical development of explosive strength. Technical elements with and without the ball will be introduced in all situations, such as: quick jump-departure with the ball at the foot and change of direction to the left and to the right. Players will play positioning roles opposite to the situation in which they normally work (left defenders will be used on the right side, etc.). In all cases, it is recommended to insist on avoiding additional movements that lead to a decrease in agility.

Key words: asymmetries, football players, agility, explosive strength.

\section{article details}

Article statistics: Word count: 1,938; Tables: 4; Figures: 2; References: 35

Full-text PDF: http://www.balticsportscience.com

Copyright @) Gdansk University of Physical Education and Sport, Poland

Indexation: Celdes, Clarivate Analytics Emerging Sources Citation Index (ESCI), CNKI Scholar (China National Knowledge Infrastructure), CNPIEC, DOAJ, EBSCO - Central \& Eastern European Academic Source, EBSCO - SPORTDiscus, EBSCO Discovery Service, Google Scholar, Index Copernicus, J-Gate, Naviga (Softweco, Primo Central (ExLibris), ProQuest - Family Health, ProQuest - Health \& Medical Complete, ProQuest - Illustrata: Health Sciences, ProQuest Nursing \& Allied Health Source, Summon (Serials Solutions/ProQuest, TDOne (TDNet), Ulrich's Periodicals Directory/ ulrichsweb, WorldCat (OCLC)

Funding: This research received no specific grant from any funding agency in the public, commercial, or not-for-profit sectors. Authors have declared that no competing interest exists. Cătălin Forțan; Faculty of Physical Education and Sport, University of Craiova; email: catalin_fortan@yahoo.com This is an open access article distributed under the terms of the Creative Commons Attribution-Non-Commercial-NoDerivatives 4.0 International (https://creativecommons.org/licenses/by-nc-nd/4.0/), which permits use, distribution, and reproduction in any medium, provided the original work is properly cited, the use is non-commercial and is otherwise in compliance with the license. 


\section{INTRODUCTION}

Physical training is an inseparable part of the athletes' preparation process at any stage of sports performance. In each period of the annual cycle, its main tasks are established in such a way that it follows the multilateral development and creates the premises for the improvement of technical-tactical procedures and actions [1-6].

Football is a total sport, and it requires parallel development of physical qualities, technical tactics, and psychological skills [7-9]. Modern football evolves rapidly, especially regarding the physical qualities $[10,11]$. This is because the football game involves many dynamic movements, including acceleration, deceleration and change of direction while running [12], and the speed in football means chasing the ball from back to front, then fast backward, leftward, rightward movements, returning to the centre of the field and dribbling and hitting the ball [13]. This is the reason why each player's dribbling or changing direction in several directions (chaotic) can be determined by the combined asymmetrical and unpredictable nature of football $[14,15]$. So, players' physical training should be materialized in higher speed indices in order to lead to well-organized game actions which will surprise the opponent $[16,17]$, and the agility and explosive strength must become indispensable qualities for a football player [18]. As a consequence, the coach must pay close attention to developing those skills throughout the game. As far as actions performed at maximum speed are concerned, the coach should develop proper management of the situations of interruption of the game, which are often trained and then premeditated during the game. Therefore, during the game, a player runs distances with or without the ball performing technical-tactical actions at different levels of cumulative intensity: physical, technicaltactical or mental $[19,20]$.

The purpose of this study was to analyse football players' explosive strength and the capacity to perform an agility test on different distances and to measure the asymmetries in changes of direction.

\section{MATERIAL AND METHODS}

\section{SUBJECTS}

Twenty male football players of an average age of 17.6 \pm 1.27 years old, height of $177.3 \pm 5.7 \mathrm{~cm}$, body mass $67.45 \pm 7.24 \mathrm{~kg}$, BMI 21.4 \pm 1.99 , and 12 hours of training per week were tested in April 2021 (Table 1). All players voluntarily participated in this study and the written informed consent was obtained from the tutors and players before starting the study.

Table 1. Demographic and anthropometric descriptive statistics of the sample

\begin{tabular}{ccccc} 
Characteristic & $\mathrm{n}$ & Min & Max & Mean \pm SD \\
\hline Age (years) & 20 & 16 & 19 & $17.6 \pm 1.27$ \\
Weight $(\mathrm{kg})$ & 20 & 50 & 85 & $67.45 \pm 7.24$ \\
Height $(\mathrm{cm})$ & 20 & 166 & 186 & $177.35 \pm 5.79$ \\
BMI & 20 & 17.80 & 24 & $21.43 \pm 1.99$ \\
\hline
\end{tabular}

\section{STUDY DESIGN}

After observing the official and friendly games played by junior football players, we found that they recorded an increase in the speed of execution in systematically repeated technical procedures, especially with the ball at their feet. For this reason, we tested both explosive strength and agility in the left and then the right leg. All assessments took place outdoors at Alexandria Football Club, Romania, on the same day, after a previous warm-up programme. 
Participants performed 3 tests for lower limb explosive strength using the Optojump system (Microgate, Bolzano, Italy) [21] (CMJ - counter movement jump, 5 jumps single leg left front/ back drift and 5 jumps single leg right front/back drift). The CMJ acquired the flight time and the height reached from the centre of gravity. According to Rado et al. [22], who tested four different portable devices used to measure a wide range of counter-derived neuromuscular parameters, Optojump showed the most accurate measurement of CMJ performance.

In order to test agility, the participants passed 4 tests of ability of changing the direction in speed, as described below (Fig. 1 and 2): each player was tested after performing an agility test - a single change of direction to the left and one to the right, then a complete turn with three changes of direction, once to the left and once to the right.

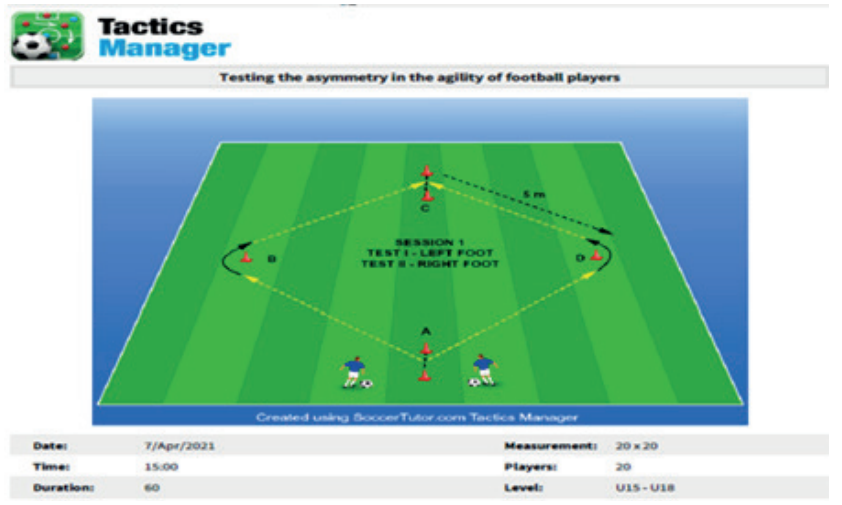

Fig. 1. Simple agility test left and right

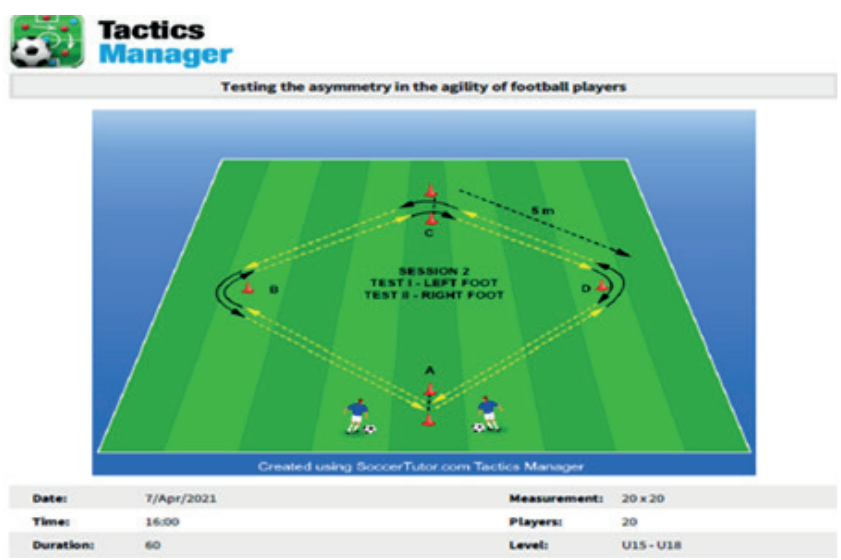

Fig. 2. Multiple agility test left and right

Objective: To develop explosive strength to the left, then to the right when changing direction with the ball at the foot.

\section{Session 1}

Test I.

1. Departure from point A to own decision - start the timer;

2. Dribble the ball with change of direction to the left - point B;

3. Speeding with the ball at the foot - point C.

Test II.

1. Departure from point A to own decision - start the timer;

2. Dribble the ball with change of direction to the right - point $D$;

3. Speeding with the ball at the foot - point $C$. 
Coaching points:

- Dribble the ball with speed;

- Coordination of movements;

- Economy of movements when changing direction;

- Optimal body position.

\section{Session 2}

Test I.

1. Departure from point A to own decision - start the timer;

2. Dribble the ball with change of direction to the left - point B, C \& D;

3. Speeding with the ball at the foot - from point A through $B, C \& D$, then back to A.

Test II.

1. Departure from point A to own decision - start the timer;

2. Dribble the ball with change of direction to the right - point $D, C \& B$;

3. Speeding with the ball at the foot - from point A through $D, C \& B$, then back to A.

Coaching points:

- Dribble the ball with speed;

- Coordination of movements;

- Economy of movements when changing direction;

- Optimal body position.

Progression: With the ball diagonally to the left, then to the right.

\section{STATISTICAL ANALYSIS}

The statistical analysis was made through SPSS, v.21. Data were reported as mean \pm standard deviation (SD), minimum and maximum values. Paired t-test was used to detect the differences between the left and the right leg on the agility tests and explosive strength.

\section{RESULTS}

Table 2 shows descriptive statistics on the Optojump test. The mean time flight from the CMJ was $0.52 \pm .042 \mathrm{~s}$, with the minimum value of $0.45 \mathrm{~s}$ and the maximum of $0.59 \mathrm{~s}$. On the second parameter of the CMJ, the highest jump was $42 \mathrm{~cm}$ and the lowest one was $25 \mathrm{~cm}$, with a mean value of $34.17 \pm 5.64$. The power for the 5 jumps front/back drift recorded a mean of $2.64 \pm 1.82$ for the left leg and $3.79 \pm 1.97$ for the right one.

The results of the agility test are presented in Table 3. For the simple agility tests, the participants obtained a mean value of $3.93 \pm 0.35 \mathrm{~s}$ for the left side and $3.87 \pm 0.25 \mathrm{~s}$ for the right one. In the multiple agility test, the mean was $7.81 \pm 0.45 \mathrm{~s}$ for the left and $7.56 \pm 0.41 \mathrm{~s}$ for the right side.

The mean differences between the left and right leg can be observed in Table 4 . For the short test agility there are no significant differences between left and right legs $(t=1.33$, $\mathrm{p}>0.05$ ). With more changes of direction, there is a significant difference in the execution time between the left side and the right side $(t=3.87, \mathrm{p}<0.05)$. Also, the means between the power of the jumps for 5 jumps front/back drift indicate a significant difference between legs $(t=-2.39, \mathrm{p}<0.05)$.

A significant relationship between explosive strength and agility was found $(r=.544, \mathrm{p}<.05)$ on the multiple test agility and 5 jumps drift, as well. 
Table 2. Descriptive statistics of explosive strength using Optojump

\begin{tabular}{|c|c|c|c|c|}
\hline Characteristic & $\mathrm{n}$ & Min & Max & Mean \pm SD \\
\hline CMJ -Time flight (sec) & 20 & .45 & .59 & $.52 \pm .042$ \\
\hline CMJ - Elevation (height-cm) & 20 & 25.00 & 42.00 & $34.17 \pm 5.64$ \\
\hline 5 jumps front/back drift left leg & 20 & .93 & 8.03 & $2.64 \pm 1.82$ \\
\hline 5 jumps front/back drift right leg & 20 & 1.40 & 8.98 & $3.79 \pm 1.97$ \\
\hline
\end{tabular}

Table 3. Descriptive statistics of the agility tests

\begin{tabular}{lllll}
\multicolumn{1}{c}{ Characteristics } & $\mathrm{n}$ & Min & Max & Mean \pm SD \\
\hline Simple agility - left (s) & 20 & 3.40 & 4.53 & $3.93 \pm 0.35$ \\
Simple agility - right (s) & 20 & 3.34 & 4.33 & $7.81 \pm 0.36$ \\
Multiple agility - left (s) & 20 & 6.99 & 8.44 & $7.56 \pm 0.41$ \\
Multiple agility - right (s) & 20 & 6.92 & 8.34 & 7.37 \\
\hline
\end{tabular}

Table 4. Mean differences between the left and the right leg

\begin{tabular}{|c|c|c|c|c|c|c|c|c|}
\hline & \multicolumn{5}{|c|}{ Differences } & \multirow[t]{3}{*}{$\mathrm{t}$} & \multirow[t]{3}{*}{ df } & \multirow{3}{*}{$\begin{array}{l}\text { Sig. } \\
\text { (2-tailed) }\end{array}$} \\
\hline & \multirow[t]{2}{*}{ Mean } & \multirow[t]{2}{*}{$\begin{array}{l}\text { Std. } \\
\text { Devia- } \\
\text { tion }\end{array}$} & \multirow[t]{2}{*}{$\begin{array}{l}\text { Std. } \\
\text { Error } \\
\text { Mean }\end{array}$} & \multicolumn{2}{|c|}{$\begin{array}{l}\text { 95\% Confidence } \\
\text { Interval of the } \\
\text { Difference }\end{array}$} & & & \\
\hline & & & & Lower & Upper & & & \\
\hline 5 jumps front/back drift left - right leg & -1.15 & 2.14 & .480 & -2.15 & -.144 & -2.39 & 19 & .027 \\
\hline Multiple test left - right & .248 & .286 & .064 & .113 & .382 & 3.87 & 19 & .001 \\
\hline
\end{tabular}

\section{DISCUSSION AND CONCLUSIONS}

In conclusion, the current study indicates that the lower limbs differences are insignificant when players are using the explosive strength of the legs only once, but there is a significant increase in execution time when they perform multiple changes of direction (agility). This can indicate an asymmetry in execution. There are many studies on asymmetries in football which suggest that a given load can detect different levels of imbalance that rarely favour the same side or direction [23-26]. Many authors suggests that dribbling and change of direction are a key to success in football [27-29]. In order to improve these two elements, the training planning must be done based on a deep knowledge of the content and forms of training, and, even if football is a team sport, the coach must also use an individual training plan [30]. In multidirectional sport, especially in football, it would be advantageous for a player to be equally competent (balanced / symmetrical) and quick to change direction from both members and directions, given the unpredictable nature and agility requirements [31]. Also, it is very important to use working methods that stimulate ambilaterality, because the bilateral symmetries of the leg strength can be affected by a single leg predominance in mobilization training [32].

Trecroci et al. [33] propose adding some additional dribbling exercises focusing on the non-dominant direction in order to improve it, without affecting the dominant direction. During the training week (preparatory or competitive part), it is recommended to insist on corrections that will refer to the development of symmetry in the football game, an aspect that will facilitate the technical-tactical manifestation of a football player in the relationship with the opponent. Therefore, the coaching points will refer to the technique without the ball (changes of direction, jumps, etc.), shooting the ball with both legs that will surprise the opponents in the game.

The model of approaching the physical training of football players is becoming an increasingly pressing issue for specialists in the domain. It is often said that for teams of 
close technical-tactical values, the physical factor will always make the difference. Players who maintain a high level of strength, endurance and speed will prevail more easily than others. This aspect is real. But in recent decades, world football has been dominated by the tactical periodization model, which is increasingly used by coaches. Barbu and Stoica [34] , 35] state that tactical periodization has replaced instructions focused on physical training, a model easier accepted by players.

To improve the speed of the game and the change of direction, we suggest the following aspects methodically staggered according to the needs of training and competition:

- the use of exercises in which players are instructed to develop their explosive strength symmetrically on both legs;

- in the warm-up and core exercises, players will work equally with both the right and left foot as follows.

In the games of possession, positioning and rounds, they will be permanently changed in such a way as to use both legs for the symmetrical development of explosive strength. Technical elements with and without the ball will be introduced in all situations, such as: quick jump-departure with the ball at the foot and change of direction to the left and to the right. Players will play positioning roles opposite to the situation in which they normally work (left defenders will be used on the right side, etc.). In all cases, it is recommended to insist on avoiding additional movements that lead to a decrease in agility.

\section{REFERENCES}

[1] Cosma G, Barbu D, Burcea B, Nanu C, Cosma A. Pregatirea fizica in sportul de performanta. Craiova: Editura Universitaria Craiova; 2017.

[2] Dragoș P, Lucaciu G, Dinis I, Ștef Gavriș M, Szabo-Alexi P, Buhaș S. Concepts Concerning the Content of Children `s Training in Some Sport Games. Proceedings of the 4th International Conference of the Universitaria Consortium (ICU 2018): The Impact of Sport and Physical Education Science on Today's Society. Bologna: Editografica S R L; 2018, 67-72

[3] Brindescu S, Buda IA. Study on the Efficiency of the Playmaker in Modern Football, In 6th International Conference of Universitaria Consortium "FEFSTIM: Physical Education, Sports and Kinesiotherapy-implications in quality of life". 2020, 13-18.

[4] Cristea DI, Motoc I, Pop AC. Aspects regarding the integration of children with special educational needs through participation in physical education. Balt J Heath Phys Act. 2020;SpecIss12(1):79-86. https://doi.org/10.29359/ BJHPA.12.Spec.Iss1.09

[5] Zadarko E, Zbigniew B, Szabo-Alexi P, et al. Physical Education and Students' Health Promotion Platform as an Element of European Union's Health Strategy Against the Level of Cardiorespiratory Fitness of Students from Poland, Slovakia, Romania. Studia Universitatis Babes-Bolyai, Educatio Artis Gymnasticae. 2011;56(3):107-116.

[6] Dragoș P, Szabo-Alexi M, Szabo-Alexi P, et al. Investigations concerning the influence of sports training carried out in a protected area (Natura 2000 site) on various physiological and biological parameters for athletes. GeoSport Soc. 2017;6(1):40-46.

[7] Gorelski Y, Kasabova L. Differences in the level of physical preparation among 13-14-year-old football players according to their position. Knowledge Int J. 2019;30(2):481-485. https://doi.org/10.35120/kij3002481g

[8] Buhaș SD, Stance L. The Relationship between Personality and Physical Activity. Geosport Soc. 2017;7(2):72-77.

[9] Brândescu S, Datcu R. Improving motor skills of children in secondary school by using means specific to football game. Timisoara Phys Educ Rehabil J. 2014;7(13):32-38.

[10] Bansbo J. Physiological demands of football. Sport Sci Exch. 2014;27(125):1-6.

[11] Brândescu S. Analysis of specialist opinions about the problem of selection in the game of football for children 6-8 years of age. Timisoara Phys Educ Rehabil J. 2014;6(12):29-34. https://doi.org/10.2478/tperj-2014-0025

[12] Matlak J, Racz L, Tihanyi J. Assessment of repeated reactive agility performance in amateur soccer players. Sci Sport. 2017;32:235-238. https://doi.org/10.1016/j.scispo.2017.06.001

[13] Womsiwor D, Adiputra N, Made Bakta I, et al. A Predominant Physical Component Profile of Persipura Junior Football Athletes. Journal Pendidikan Jasmani dan Olahraga JPJO. 2020;5(1):55-61. https://doi.org/10.17509/jpjo.v5i1.23792

[14] Bishop C, Read P, Chavdna S, et al. Magnitude or direction? Seasonal variation of interlimb asymmetry in elite academy soccer players. J Strength Condition Rese. 2020;1. https://doi.org/10.1519/JSC.0000000000003565

[15] Brândescu S. Study on the psycho-motor profile of the central defender in Romanian football. Timisoara Phys Educ Rehabil J. 2013;6(11):36-41. https://doi.org/10.2478/tperj-2013-0014

[16] Barbu D, Stoica D. Increasing the execution speed of offensive and defensive tactical actions in the football game at the time of transition. J Sport Kinetic Move. 2020;36(II):5-13.

[17] Herman GV, Banto N, Caciora T, et al. Tourism in Bihor Country, Romania. Trends and Prospects. Folia Geogr 2020;62:87-105 
[18] Cristea D, Cristea A, Dragos P. Considerations regarding pedagogical practice of physical education students at gymnasium. GeoSport Soc. 2017;6(47).

[19] Ilieș DC, Buhaș R, Ilieș A, et al. Indoor Air Quality Issues. Case Study: The Multipurpose Sport Hall of the University of Oradea. Environ Eng Manag J (EEMJ). 2018;17(12):2999-3005. https://doi.org/10.30638/eemj.2018.300

[20] Brândescu S. Analysis of specialist opinion about the problem of selection in the game of football for children 6-8 years of age. Timisoara Phys Educ Rehabil J. 2015;7(14):46-50. https://doi.org/10.1515/tperj-2015-0007

[21] Counter Movement Jump. http://www.optojump.com/Applications/Test-Typologies/Counter-Movement-Jump.aspx

[22] Rago V, Brito J, Figueiredo P, et al. Countermovement jump analysis using different portable devices: implications for field testing. Sports (Basel). 2018;6(3):91. https://doi.org/10.3390/sports6030091

[23] Dos 'Santos T, Thomas C, Jones P, Comfort P. Asymmetries in single and triple hop are not detrimental to change of direction speed. J Trainol. 2017;6:35-41. https://doi.org/10.17338/trainology.6.2_35

[24] Bishop C, Turner A, Maloney S, Lake J, Loturco I, Bromley T, Read P. Drop jump asymmetry is associated with reduce sprint and chance-of-direction speed performance in adult female soccer players. Sports. 2019;7:29. https://doi. org/10.3390/sports7010029

[25] Trecroci A, Formenti D, Ludwig N, Gargano M, Bosio A, Rampinini E, Alberti G. Bilateral asymmetry of skin temperature is not related to bilateral asymmetry of crank torque during an incremental cycling exercise to exhaustion. Peer J. 2018;6:e4438. https://doi.org/10.7717/peerj.4438

[26] Bishop C, Turner A, Jarvis P, Chavda S, Read P. Considerations for selecting field-based strength and power fitness tests to measure asymmetries. J Strength Condit Res. 2017;31:2635-2644. https://doi.org/10.1519/JSC.0000000000002023

[27] Trecroci A, Longo S, Perri E, Iaia F, Alberti G. Field-based performance of elite and sub-elite middle-adolescent soccer players. Res Sports Med. 2019:27:60-71. https://doi.org/10.1080/15438627.2018.1504217

[28] Trecroci A, Milanovic Z, Marcello I. Physical performance comparison between under 15 elite and sub-elite soccer players. J Hum Kinet. 2018;61:209-216. https://doi.org/10.1515/hukin-2017-0126

[29] Valente-dos-Santos J, Coelho-e-Silva M, Duarte J, et al. Allometric multilevel modelling of agility and dribbling speed by skeletal age and playing position in youth soccer players. Int J Sports Med. 2014;35:762-771. https://doi. org/10.1055/s-0033-1358469

[30] Barbu D. Teoria și practica în fotbalul de performanță. Editura Universitaria Craiova [Theory and practice in football]. Universitaria Publisher; 2012, 203] Romanian.

[31] Dos'Santos T, Thomas C, Jones PA, Comfort P. Assessing asymmetries in change of direction speed performance; application of change of direction deficit. J Strength Cond Res. 2019;33(11):2953-2961. https://doi.org/10.1519/ JSC.0000000000002438

[32] Yildiz M, Kale M. The effects of kicking leg preference on the bilateral leg strength asymmetries of amateur football players. Isokinetics Exerc Sci. 2018;26:1:37-42. https://doi.org/10.3233/IES-171159

[33] Trecroci A, Bongiovanni T, Cavaggioni L, Pasta G, Formenti D, Alberti G. Agreement between dribble and change of direction deficits to assess directional asymmetry in young elite football players. Symmetry. 2020;12(5):787. https:// doi.org/10.3390/sym12050787

[34] Barbu D, Stoica D. Scientific approach of tactical training in football game with children and junior players. J Sport Kinetic Move. 2018;32(2):54-60.

[35] Chivu I-D. Elementele tehnice ale actiunilor tactice colective de atac in jocul de fotbal. Studia Universitatis Vasile Goldis. Phys Educ Phys Ther Series. 2018;7(2):29-34. 